\title{
Charles Baudelaire, Salon de 1839
}

\section{Mario Richter}

\section{(2) OpenEdition}

\section{Journals}

\section{Edizione digitale}

URL: http://journals.openedition.org/studifrancesi/9621

DOI: 10.4000/studifrancesi.9621

ISSN: 2427-5856

\section{Editore}

Rosenberg \& Sellier

\section{Edizione cartacea}

Data di pubblicazione: 1 décembre 2007

Paginazione: 686-687

ISSN: 0039-2944

\section{Notizia bibliografica digitale}

Mario Richter, «Charles Baudelaire, Salon de 1839», Studi Francesi [Online], 153 (LI | III) | 2007, online da 30 novembre 2015, consultato il 12 janvier 2021. URL: http://journals.openedition.org/studifrancesi/ 9621 ; DOI: https://doi.org/10.4000/studifrancesi.9621

Questo documento è stato generato automaticamente il 12 janvier 2021.

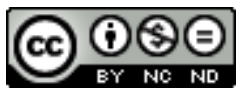

Studi Francesi è distribuita con Licenza Creative Commons Attribuzione - Non commerciale - Non opere derivate 4.0 Internazionale. 


\title{
Charles Baudelaire, Salon de 1839
}

\author{
Mario Richter
}

\section{NOTIZIA}

CHARLES BAUDELAIRE, Salon de 1839. Texte de la Revue française, établi avec un relevé de variantes, un commentaire et une étude sur Baudelaire critique de l'art contemporain par Wolfgang DROST avec la collaboration de Ulrike RIECHERS, édition illustrée de 173 reproductions, Paris, Champion, 2006, pp. 899.

Dopo averci dato nel 1992 il testo, filologicamente e sapientemente commentato, dell'Exposition de 1859 di Théophile Gautier, W. Drost (con l'ausilio di U. Riechers), ci fornisce ora anche quello di Baudelaire, il Salon de 1859, nella versione originale della «Revue française». Al di là della presentazione criticamente ineccepibile del testo (del quale sono segnalate le varianti), questo volume si raccomanda soprattutto per la solidità del ricchissimo commento, dal quale è possibile conoscere nel migliore dei modi tutto il complesso contesto del Salon nella sua realtà storicamente verificabile. Trattandosi tuttavia di una massa di dati inevitabilmente trattati in rapporto al procedere del testo baudelairiano e dunque non raggruppati secondo un criterio tematico, il curatore ha avuto la felice idea di venire incontro al lettore con una "synthèse du commentaire" intitolata «Baudelaire critique de l'art contemporain». Una prima parte di argomenti (Le Salon de 1859, un manifeste anti-réaliste, L'abolition des limites de la peinture d'histoire et de genre, Le regard en profondeur: la transfiguration de la réalité, Mysticisme esthétique et néo-baroque, Du règne de l'imagination et de la création de l'infini, Coleridge, Cousin et la décomposition poétique de l'univers, La fantaisie dans l'art, Le charme étrange de l'art anglais) dalla quale si apprende, nella sostanza e al di là delle frequenti sfumature, che «l'anti-réalisme de Baudelaire a pour pendant l'apothéose de l'imagination» e che «entre la tension de ces deux pôles se déroule en multiples facettes son dialogue avec les peintres contemporains et leurs œuvres», è radunata sotto il significativo titolo «Défense et illustration de l'imagination». Seguono «La Photographie» (La philippique contre la photographie), «Le Portrait» (Portrait et photographie, L'éclectisme dans l'art du portrait, Caricature 
et physionomie), «La Peinture de paysage» (La naissance de la peinture de paysage, La nature vue à travers un tempérament, Facture et impression avant l'impressionnisme, L'étude est-elle un tableau?, Un survivant du romantisme, L'esthétique du mensonge et du décor, L'idéalisme allemand et l'esthétique symboliste anticipée, Le refus de l'engagement et la recherche de l'idylle), «La Sculpture» (L'imitation de l'antiquité comme défi à la créativité, Le nouveau point de vue baudelairien, Le débat sur le paragone: la primauté de la peinture, Renaissance bellifontaine et néo-baroque, Le spiritualisme dans la sculpture), «Positions esthétiques de Baudelaire» (De la critique associative à l'abstraction, Vers un concept de modernité). L'indagine articolata di Drost porta a modificare alcune idee correnti riguardanti il Baudelaire critico d'arte. L'ideale artistico del poeta sembra realizzarsi soltanto nel quadro di Delacroix Ovide en exil chez les Scytes. L'Angélus di Legros è per lui esempio della collaborazione creatrice fra lo spettatore e l'opera d'arte. Per quanto concerne la proiezione di Baudelaire verso la modernità, Drost assume un atteggiamento di prudente equilibrio: «Baudelaire, auteur $\mathrm{du}$ Salon de 1859, ne correspond pas toujours à l'image que l'on se fait d'un critique d'avant-garde [...] S'il passe sous silence Puvis de Chavannes dont Gautier dévouvre le génie, s'il n'a pas l'intuition de l'essor que la peinture de paysage va prendre dans l'impressionnisme, il a le mérite d'introduire l'eau-fortiste Charles Meryon et Victor Hugo dessinateur [...] Sa critique d'art nous met à même de reconstituer l'univers imaginaire du poète et le Salon de 1859 en particulier nous permet de voir un grand critique d'art du xix ${ }^{e}$ siècle européen s'acheminer vers une théorie de la modernité». Il volume, che è impreziosito da 173 riproduzioni di opere d'arte note e meno note, si conclude con una esauriente bibliografia e con un utilissimo «Index rerum et personarum». 